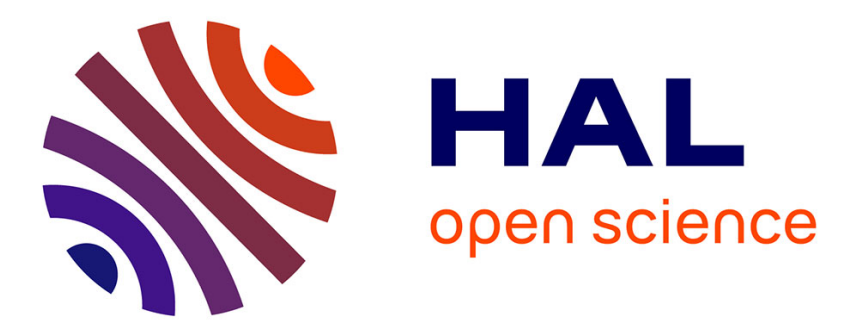

\title{
Everyday geography and service accessibility: The contours of disadvantage in relation to mental health
}

Julie Vallée, Martine Shareck, Yan Kestens, Katherine L Frohlich

\section{To cite this version:}

Julie Vallée, Martine Shareck, Yan Kestens, Katherine L Frohlich. Everyday geography and service accessibility: The contours of disadvantage in relation to mental health. Annals of the Association of American Geographers, 2022, 112, 4, pp.931-947. 10.1080/24694452.2021.1940824 . hal-03343684

\section{HAL Id: hal-03343684 \\ https://hal.science/hal-03343684}

Submitted on 14 Sep 2021

HAL is a multi-disciplinary open access archive for the deposit and dissemination of scientific research documents, whether they are published or not. The documents may come from teaching and research institutions in France or abroad, or from public or private research centers.
L'archive ouverte pluridisciplinaire HAL, est destinée au dépôt et à la diffusion de documents scientifiques de niveau recherche, publiés ou non, émanant des établissements d'enseignement et de recherche français ou étrangers, des laboratoires publics ou privés. 


\title{
EVERYDAY GEOGRAPHY AND SERVICE ACCESSIBILITY: THE CONTOURS OF DISADVANTAGE IN RELATION TO MENTAL HEALTH
}

\author{
Julie Vallée ${ }^{1}$, Martine Shareck ${ }^{2}$, Yan Kestens ${ }^{3}$, Katherine L. Frohlich ${ }^{3}$ \\ ${ }^{1}$ Centre National de la Recherche Scientifique (CNRS), UMR Géographie-cités, Paris-Aubervilliers, \\ France \\ ${ }^{2}$ Département des sciences de la santé communautaire, Université de Sherbrooke, Canada, and Centre de \\ Recherche du Centre Hospitalier de l'Université de Sherbrooke, Canada \\ ${ }^{3}$ École de santé publique de l'Université de Montréal, Montréal, Canada and Centre de recherche en santé \\ Publique (CReSP) de l'Université de Montréal, Montréal, Canada
}

\begin{abstract}
This paper investigates everyday geography of young adults and the unequal importance which spatial accessibility to a range of urban services may have for their mental health in order to identify those who are 'truly disadvantaged'. While the literature on the socially differentiated vulnerability to place effects has traditionally focused on the neighbourhood of residence, we consider daily activity locations to explore if socially disadvantaged populations are more exposed to ('differential exposure') and/or more affected by ('differential effect') low spatial accessibility to services compared to their more advantaged counterparts. Data came from 1,983 young adults (18-25 years-old) living in Montreal, Canada. We observed that less educated young adults had a lower spatial accessibility to services in their activity space than their more educated counterparts, but also that they were more vulnerable to having lower numbers of services in their surroundings: lower service accessibility in the activity space was associated with poorer mental health among less educated young adults but not among the more educated. We suggest three socio-spatial mechanisms related to (i) place experiences, (ii) flexibility in spatial behaviour and (iii) rules regulating actual access to services to explore why the 'objective' lack of services close to residential and activity locations may represent a greater burden to more socially disadvantaged people.
\end{abstract}

\section{Keywords}

activity space; daily mobility; mental health; neighbourhood effects; social vulnerability. 


\section{Introduction}

Decades of research indicate a strong persistence of social inequalities in key indicators such as health outcomes or educational attainment, even in countries with social protection systems (Mackenbach 2012). It is in this context that neighbourhood effects and urban segregation remain critical areas of debate. In response to conservative tendencies to blame the most socially excluded groups (e.g., unemployed individuals, ethnic minorities or low-income households) for their situation, progressive scholars have argued that vulnerable subgroups' social exclusion can be largely explained by social structures and public policies. Towards the end of the 1980's, Wilson brought attention, in The Truly Disadvantaged (1987), to the fact that individual poverty matters more strongly in neighbourhoods where the population is overwhelmingly socially disadvantaged. Poor people often have to deal with a double burden: they have to grapple with the multiple problems arising from their own lack of income and also to deal with the social effects of living in a poor neighbourhood. Introducing the notion of 'concentration effects', Wilson suggested that poor people may be particularly vulnerable to neighbourhood effects because they lack the collective resources and 'social buffers' which more advantaged people benefit from. The idea of concentration effects is at the heart of criticisms regarding the frequent and artificial separation between individual and contextual effects in the neighbourhood effects literature (Macintyre, Ellaway, and Cummins 2002) or about liberal readings of the 'capability approach' which leave little room for the role of social and spatial structures in shaping the choices individuals perceive as possible, and ultimately make (Bowman 2010). In line with the relational approach to place (Cummins et al. 2007; Jones 2009) and considering that place interacts with people and may exert a differential impact on people according to their social class, we aim to investigate the socially differentiated vulnerability to place effects on health in order to identify those who are 'truly disadvantaged'.

\section{Socially differentiated vulnerability to place effects}

Residential features including physical and social infrastructure, inadequate employment, training and educational opportunities, and the collective social functioning and practices (e.g., local norms, neighbourhood reputation, social capital and cohesion) have been shown to impact inhabitants' standards of living. Empirical studies have also demonstrated statistically significant interactions between residential features and individual socio-economic position on social and health outcomes. In relation to selfrated health, studies from England and Scotland have found that, over and above individual age, sex, and social class, living in neighbourhoods with lower densities of health services or with lower access to private transport had a greater impact on the selfrated health of those who were unemployed than those who were in employment (Cummins et al. 2005). In another British study, the association between mental disorders and neighbourhood deprivation was only significant among people who were economically inactive (Weich et al. 2003). In the southeast of England, the effects of living in a deprived area on general and mental health were found to be larger for individuals of lower socio-economic status (Stafford and Marmot 2003). Significant interactions between residential features and individual socioeconomic position have also been observed for diet-related outcomes. In France, the risk of being overweight was found to be linked with the neighbourhood socioeconomic environment among bluecollar workers only (Chaix and Chauvin 2003). In the Netherlands, risk of overweight 
was found to increase by neighbourhood deprivation level within each individual educational group, except for the most educated (van Lenthe and Mackenbach 2002). In Vientiane city (Lao PDR), the risk of hypertension, overweight and anemia were found to be more strongly associated with the level of urbanization of residential neighbourhoods among poor than among rich inhabitants (Vallée 2009). In Scotland, as alcohol outlet densities increased, the probability of alcohol consumption raised among poor people, while it remained relatively stable for rich people (Shortt et al. 2018). These results suggest that "lower income groups might be disproportionately affected by outlet density" and that there could be "a socially differentiated vulnerability" to residential features (Shortt et al. 2018, p 1223).

These empirical studies - which remain relatively scarce compared to the growing literature on neighbourhood effects on health (Oakes et al. 2015) - have shown that socially disadvantaged groups may be more vulnerable to residential features than their more socially advantaged counterparts. Authors unanimously relate exposure to local socio-environmental conditions to daily mobility and the resulting time spent in the neighbourhood: "for subjects in lower socioeconomic groups (...) the neighbourhood environment may have a larger impact on daily life than for subjects in higher socioeconomic groups (...) at least partly because the first groups presumably spend more time in their neighbourhoods." (van Lenthe and Mackenbach 2002, p 235).

\section{Vulnerability to place effects and daily mobility}

Accounting for people's daily mobility may actually explain why residential neighbourhood features do not impact everyone equally. People whose activity space (i.e., the space within which they move about or travel in the course of their daily activities) is limited to their neighbourhood of residence are more strongly dependent on the residential features than people with larger activity spaces when exploring selfreported mental health (Inagami, Cohen, and Finch 2007), depression (Vallée et al. 2011) or health-seeking behaviours (Vallée et al. 2010; Vallée and Chauvin 2012). The daily mobility argument also finds echo in the gentrification literature where some authors have suggested that neighbourhood dislocations produced by gentrification were most harmful to lower income groups (who may be more tied to the neighbourhood-based social fabric and systems of support, exchange and reciprocity because of their limited daily mobility) than to middle and upper income groups (Betancur 2011).

People's daily mobility and their everyday geography - relating to places that people experience in everyday life - is arousing an interest in geography (Golledge and Stimson 1997), starting with 'time-geography'(Hägerstrand 1970) but also in the social sciences in general, notably with the new "mobility turn" paradigm (Sheller and Urry 2006). In the place effects literature, daily mobility has been put forward to discuss why different social subgroups may be unequally affected by residential features. However, it remains to be explored if the socially differentiated vulnerability to place effects extends over differences in daily mobility patterns. As underlined by Shareck et al. (2014a), several studies have previously compared measures of exposure to environmental conditions between residential and activity space contexts and some others have investigated the association between environmental conditions and health while considering people's experience of multiple settings. However the social inequalities in activity space regarding both exposures and vulnerabilities remain less explored: socioeconomic status is rarely considered as a potential moderator of the effect of activity space features on 
health outcomes (Shareck et al. 2020).

\section{Relating mental health to service accessibility}

In this paper we explore how young adults' self-reported mental health differs according to their spatial accessibility to services from their residential and regular activity locations. We consider a diversity of urban services, not only mental health services, but also commercial, cultural, transportation and leisure facilities. These services are chosen on the basis of a framework of how places might meet universal human needs required for a healthy life. Density of (or proximity to) urban services in everyday life may be related to social inclusion and spatial justice. Accessibility "is fundamentally about the life opportunities open to people. It is not a sufficient condition for social inclusion and social justice, but it is a necessary one" (Farrington and Farrington 2005). As a marker of the opportunities people have to engage with societal activities, services accessibility has been associated related with a range of psychosocial and mental health outcomes in the neighbourhood and health literature (Cummins et al. 2005; Maas et al. 2006; Kim 2008; Leslie and Cerin 2008; Mair, Diez Roux, and Galea 2008), but also in the literature on transport disadvantage and social exclusion (Delbosc 2012).

When exploring the impact of service accessibility in everyday life on mental health, there is a need to make a clear distinction between accessibility and mobility as the two terms are often used interchangeably (Fol and Gallez 2014). An extended daily mobility does not automatically mean higher service accessibility and better mental health outcomes. When limited daily mobility concerns inhabitants of disadvantaged areas, it may reflect a spatial and social confinement and be correlated with a higher risk of poor mental health. When limited daily mobility concerns people living in advantaged areas, it may conversely reflect a deep neighbourhood attachment and be correlated with a lower risk of poor mental health. What really makes the difference is not mobility per se but the material and social features of the neighbourhood of residence and its ability to meet personal needs (Vallée et al. 2011).

Besides, environmental features promoting mobility do not automatically correlate with better mental health outcomes: it may depend on the kind of mobility under consideration. On the one hand, active mobility-friendly environments (e.g., with high land use mix, pedestrian and cycling infrastructures, good quality public transportation) may encourage physical activity (Sallis et al. 2004) and enhance mental health (Liu et al. 2017). On the other hand, car-centred (and noisy) environments may negatively impact mental health (Passchier-Vermeer and Passchier 2000), notably for lower income individuals facing a doubly unfair situation since they often live close to major traffic routes and are less likely to be protected by noise barriers (Potvin, Apparicio, and Séguin 2019).

The whole spectrum of mobility opportunities and nuisances operate in urban areas, making them a relevant laboratory to explore social inequalities in service accessibility in everyday life, and ultimately assess the socially differentiated effects of service accessibility on mental health.

\section{A focus on young adults}

By focusing on young adults, we shed light on young adulthood as a key transitional period, critical in the course of psychopathology and mental health (Schulenberg, Sameroff, and Cicchetti 2004). Most mental health disorders begin during youth (12-24 
years of age), although they are often detected later in life (Patel et al. 2007). The cumulative disadvantage theory emphasizes the role of accumulated risks that produce educational inequalities in health over the life course (Seabrook and Avison 2012). The transportation literature rarely focuses on young adults: numerous studies in fact concern elderly populations and explore the consequences of driving cessation and of mobility limitations on healthy ageing. Another facet of the literature concerns children's independent mobility and how it relates to health and well-being (Depeau 2017). Young adults remain rarely investigated even though important changes occur towards the end of adolescence and in early adulthood, with the entry into higher education and/or the work force. During this period, patterns of attachment, support, and emotional connection shift from parents (and the home and residential neighbourhood context) to other relations and places, often far from home (Dubreuil et al. 2020; Cicognani, Albanesi, and Zani 2008) .

\section{Main objectives}

Using data collected among young adults in Montreal, Canada, we aim to (1) assess and compare the association between self-rated mental health and spatial accessibility to services when spatial accessibility: (i) is based on the residential location solely, or; (ii) accounts for individuals' daily mobility; and (2) explore if the association between mental health and spatial accessibility to services is stronger among less educated than among more educated young people. Finally, in light of the empirical findings, we discuss several socio-spatial mechanisms (related to place experiences, flexibility in spatial behaviour and rules regulating actual access to services) to explore why people sharing same residential and regular activity locations may have different access to services and why the 'objective' lack of services may represent a greater burden to more socially disadvantaged people.

\section{Materials and methods}

\section{Study design and sample}

Data come from the Interdisciplinary Study of Inequalities in Smoking (ISIS) conducted among 2,093 young adults. Participants were initially recruited from a random sample of 6,020 non-institutionalized individuals aged 18 to 25 years living in each of the 35 Local Community Health Centers (CLSC) catchment areas on the island of Montreal, Canada. Eligibility criteria included being fluent in French or English and having lived for at least 1 year at the current address at time of first contact. Non-eligible individuals $(n=458)$ were removed from the denominator for the computation of the response proportion. There were 349 individuals who explicitly refused to take part in the study, whereas 3111 others simply did not respond to invitation, making for a final response proportion of $37.6 \%$. Full details on procedures are available elsewhere (Frohlich et al. 2017). Ethical approval was obtained from the Research Ethics Committee of the Universite de Montréal's Faculty of Medicine.

\section{Data}

Socio-demographic and mental health data along with activity location information were collected with a questionnaire self-administered online (90\%) or on paper (4\%), or over 
the phone with a trained research assistant (6\%). Participants provided written or verbal informed consent prior to questionnaire completion and were rewarded with a $10 \$$ gift card for their participation. A total of 2,093 young adults took part in the ISIS study between November 2011 and September 2012 i.e., throughout the different seasons in Montreal which limits the potential seasonality impact on transportation habits, activity locations engaged with or self-reported mental health.

Activity location data were collected using an activity-based questionnaire. Participants were asked to report: (1) if they regularly conducted any of the following activities: studying, working, grocery shopping, sports or physical activity, leisure activity, and up to two other unspecified activities, and; (2) if yes, to provide location information in as much detail as possible (name, address, street, intersection/landmark, city) to allow precise geocoding. The questionnaire had high 2 -week test-retest reliability and convergent validity when compared to a 7-day continuous Global Positioning System track and a prompted-recall survey completed by independent samples (Shareck, Kestens, and Gauvin 2013). For the whole sample of 2,093 young adults, 4638 out-of-home activity locations were geocoded. The 'unspecified activities' (with 519 out-of-home locations) concerned mainly social and leisure activities.

The location of services was extracted from the 2012 DMTI Enhanced Points of Interest (EPOI) geodatabase (https://www.dmtispatial.com/) which provides, for each service listed, a name, postal address, geographic coordinates, as well as Standard Industrial Classification (SIC). We identified more than 35,000 services in the Greater Montreal Region relating to "human needs", i.e., food stores, clothing stores, eating and drinking establishments, retail stores, banking establishments, social organizations, recreational facilities, and primary health services.

\section{Measures}

We used a one-item question regarding self-rated mental health which has been found to be strongly and consistently associated with morbidity measures but also with health problems, service utilization, and service satisfaction (Ahmad et al. 2014), notably in the Canadian population (Mawani and Gilmour 2010). Self-rated health measures - even if they can be biased according to social desirability- are widely used in population surveys (for example in the Canadian Community Health Surveys) notably because of the simplicity with which they are collected and the wide range of associations with other health indicators irrespective of the time period, country and age group studied (Idler and Benyamini 1997; Jylhä 2009). Self-rated health is often measured by asking respondents how they would rate their health compared to their peers, i.e. people of their age group (Eriksson, Undén, and Elofsson 2001). Questions on self-reported health relative to others of a similar age mainly concern health 'at large' but can also refer more specifically to mental health, notably in Canadian surveys (Grenier et al. 2009; Veenstra 2011). In ISIS Study, self-reported mental health was assessed with the question "Compared to other people your age, would you say that, in general, your mental health is..." with response options provided on a 5-level Likert scale: excellent, very good, pretty good, fair, poor. Mental health status was dichotomized as good (excellent, very good and pretty good) or poor (fair and poor).

Level of education was defined as the highest level young adults had completed (for nonstudents) or were enrolled in (for current students - 70\% of the sample) by imputation of the level taught at the educational establishment attended at the time of survey. Education 
level is thought to be a better indicator of young people's socio-economic status than income or occupational class (Galobardes et al. 2006). Furthermore, in an ancillary paper, the level of education enrolled in at baseline was found to better reflect the educational level attained two years later compared to the level of education completed at baseline (Gagné et al. 2018). Three educational categories were created: high school education or less ( $\leq 11$ years of schooling), post-secondary education (12-13 years of schooling CEGEP/trade school (CEGEP refers to post-secondary educational institutions found only in Québec, Canada) and university education (14+ years of schooling).

Participants' residential and activity locations were geocoded and served as anchor points for delineating 800-meter circular buffers. The buffer size was chosen in accordance with the median size of the self-reported neighbourhood of residence among respondents (Vallée et al. 2020). Participants' residential areas were operationalized as the buffer centred on their residential location, while activity spaces were defined as the combination of buffers around each participant's residential and unique out-of-home activity locations. We operationalized service accessibility in residential areas as the number of services located in the residential buffers, and activity space accessibility as the mean number of services located in the buffers making up each participant's activity space. Both measures were categorized with the following cut points: $<100$ services (low number, i.e., low accessibility), 100-200 services (intermediate), >200 services (large number, i.e., high accessibility). Cut-offs were chosen to include at least $20 \%$ of respondents in each of the three categories of accessibility, and to be similar for both accessibility measures (residential or activity space measure).

Finally, we considered two variables related to spatial behaviour for which we assessed the related social gradient: the number of out-of-home activity locations and access to a car and public transport pass (active transportation such as cycling was not collected in the questionnaire). Three categories of out-of-home activity locations $(0 ; 1-2 ; 3-8)$ were defined after examining the distribution (mean number of 2.2 per participant with a standard deviation of 1.4). Access to motorized transportation was combined as follows: access to a car and monthly public transit pass, access to a car only, monthly public transit pass only, no access to a car and no monthly public transit pass.

\section{Statistical methods}

Spatial behaviour and measures of spatial accessibility to services were described for the complete sample and compared across education levels using nonparametric tests for trend across ordered groups ('nptrend' command in Stata 11). Logistic regression models served to estimate odds ratios and $95 \%$ confidence intervals for the association between mental health and each independent and covariate variable (bivariate models), and between mental health and residential and activity space accessibility adjusting for selected covariates (separate multivariate models for each accessibility measure). To assess whether education level modified the association between accessibility to services and mental health, logistic regression models adjusted for age, sex and access to motorized transportation were built, which included an interaction term between education level and accessibility to services (residential area or activity space measure). Three models stratified by education level were built. We assessed the presence of heterogeneous effects between educational subgroups conducting Cochran Q tests (Benmarhnia et al. 2015). Multilevel models were used to account for the clustered sampling design where between 37 and 76 (mean of 57) participants lived in each of 35 
CLSC territories ('xtmelogit' command in Stata11, specifying CLSC territories as the clustering variable). Sensitivity analyses were conducted to explore interactions and heterogeneous effects when accessibility measures were computed with 500- and 800meter road-network buffers. Statistically significant associations and interactions in all statistical analyses were defined as a probability less than 0.05 that the associations were random.

\section{Results}

Of the initial sample of 2,093 participants, 39 studied or worked outside the Greater Montreal Region and were excluded as our focus was on young adults who experienced the Island of Montreal (the study territory) on a daily basis. We also excluded 71 respondents with missing data on self-rated mental health $(n=17)$ and/or education level $(n=10)$, and/or measures of access to motorized transportation $(n=49)$. The final analytical sample of 1,983 young adults is described in Table 1 . Approximately $9 \%$ of participants reported poor mental health $(\mathrm{n}=183)$. In terms of education, $44.3 \%$ of participants had attained the University level and 17.2\% the High school level. Most had access to some motorized modes of transportation, with only $6.6 \%$ of participants having neither access to a car nor a monthly public transit pass. The majority of participants $(57.2 \%)$ reported 1 or 2 out-of-home activity locations, while $6.4 \%$ reported none. The number of services close to participants' residential locations was lower than the mean number of resources close to residential and regular activity locations, with median values of 113 and 220 services respectively. As one might expect, the proportion of respondents with spatial accessibility to a large number of services (more than 200) was higher in the activity space than in the residential area only $(53.3 \%$ vs. $29.1 \%)$.

The baseline ISIS sample was similar to Montreal participants of the Canadian Community Health Survey (CCHS) in terms of age and sex composition although proportionally, the former tended to be more educated and in worse physical and mental health than the latter (Frohlich et al. 2017).

\section{Social gradient in spatial behaviour and in spatial accessibility to services}

A significant trend can be observed in access to motorized transportation with the proportion of young adults with both access to a car and monthly public transit pass increasing from $19.3 \%$ among respondents with a High school education or less to $38.7 \%$ among respondents with a Post-secondary education, and 50\% among respondents with a University education. The number of out-of-home activity locations was also found to increase with educational level (Table 2). 
Table 1. Descriptive statistics for 1,983 young adults from the ISIS study (Montreal, Canada, 2011-2012)

\begin{tabular}{|c|c|}
\hline & $\mathrm{n}(\%)$ \\
\hline $\begin{array}{l}\text { Self-rated mental health } \\
\text { Poor } \\
\text { Good }\end{array}$ & $\begin{array}{l}183(9.2) \\
1,800(90.8)\end{array}$ \\
\hline $\begin{array}{l}\text { Sex } \\
\text { Female } \\
\text { Male }\end{array}$ & $\begin{array}{l}1,123(56.6) \\
860(43.4)\end{array}$ \\
\hline $\begin{array}{l}\text { Age } \\
18-20 \text { years } \\
21-22 \text { years } \\
23-25 \text { years }\end{array}$ & $\begin{array}{l}766(38.6) \\
500(25.2) \\
717(36.2)\end{array}$ \\
\hline $\begin{array}{l}\text { Living with parents } \\
\text { Yes } \\
\text { No }\end{array}$ & $\begin{array}{l}1,514(76,3) \\
469(23.7)\end{array}$ \\
\hline $\begin{array}{l}\text { Education level } \\
\text { High school or less } \\
\text { Post-secondary }{ }^{1} \\
\text { University }\end{array}$ & $\begin{array}{l}341(17.2) \\
764(38.5) \\
878(44.3)\end{array}$ \\
\hline $\begin{array}{l}\text { Access to motorized transportation } \\
\text { No access to a car, no monthly public transit pass } \\
\text { Monthly public transit pass only } \\
\text { Access to a car only } \\
\text { Access to a car and monthly public transit pass }\end{array}$ & $\begin{array}{l}131(6.6) \\
565(28.5) \\
486(24.5) \\
801(40.3)\end{array}$ \\
\hline $\begin{array}{l}\text { Number of out-of-home activity locations } \\
\text { As continuous variable: [Mean ; SD] } \\
\text { None } \\
\text { Small number }(1-2) \\
\text { Large number }(3-8)\end{array}$ & $\begin{array}{l}{[3.2 ; 1.4]} \\
127(6.4) \\
1135(57.2) \\
721(36.4)\end{array}$ \\
\hline $\begin{array}{l}\text { Accessibility in residential area - Number of services close } \mathbf{c}^{2} \text { to } \\
\text { residential location } \\
\text { As continuous variable: [Median ; Q1-Q3] } \\
\text { Small number }(<100) \\
\text { Intermediate number }(100-200) \\
\text { Large number }(>200)\end{array}$ & $\begin{array}{l}{[113 ; 52-221]} \\
930(46.9) \\
476(24.0) \\
577(29.1)\end{array}$ \\
\hline $\begin{array}{l}\text { Accessibility in activity space : Mean number of services close }{ }^{2} \text { to } \\
\text { residential and regular activity locations } \\
\text { As continuous variable: [Median ; Q1-Q3] } \\
\text { Small number }(<100) \\
\text { Intermediate number }(100-200) \\
\text { Large number }(>200)\end{array}$ & $\begin{array}{l}{[220 ; 112-465]} \\
424(21.4) \\
501(25.3) \\
1,058(53.3)\end{array}$ \\
\hline
\end{tabular}

${ }^{1}$ CEGEP/trade school (CEGEP refers to post-secondary educational institutions found only in Québec, Canada)

2 800-meter circular buffer 
Table 2. Trend in spatial behaviour and accessibility to services according to education level among 1,983 ISIS respondents (Montreal, Canada, 2011-2012).

\begin{tabular}{|c|c|c|c|c|}
\hline & $\begin{array}{l}\text { High school or } \\
\text { less } n=341\end{array}$ & $\begin{array}{l}\text { Post-secondary } \\
\mathrm{n}=764\end{array}$ & $\begin{array}{l}\text { University } \\
\mathrm{n}=878\end{array}$ & \multirow{2}{*}{$\begin{array}{l}\text { Trend test } \\
P \text {-value }\end{array}$} \\
\hline & \multicolumn{3}{|l|}{$\mathrm{n}(\%)$} & \\
\hline $\begin{array}{l}\text { Access to motorized transportation } \\
\text { No access to a car, no monthly public transit pass } \\
\text { Monthly public transit pass only } \\
\text { Access to a car only } \\
\text { Access to a car and monthly public transit pass }\end{array}$ & $\begin{array}{l}62(18.2) \\
98(28.7) \\
115(33.7) \\
66(19.3)\end{array}$ & $\begin{array}{l}38(5.0) \\
220(28.8) \\
210(27.5) \\
296(38.7)\end{array}$ & $\begin{array}{l}31(3.5) \\
247(28.1) \\
161(18.3) \\
439(50.0)\end{array}$ & $<0.01$ \\
\hline $\begin{array}{l}\text { Number of out-of-home activity locations } \\
\text { As a continuous variable : [Mean ; SD] } \\
\text { None } \\
\text { Small number (1-2) } \\
\text { Large number (3-8) }\end{array}$ & $\begin{array}{l}{[2.6 ; 1.3]} \\
72(21.1) \\
195(57.2) \\
74(21.7)\end{array}$ & $\begin{array}{l}{[3.1 ; 1.2]} \\
38(5.0) \\
483(63.2) \\
243(31.8)\end{array}$ & $\begin{array}{l}{[3.6 ; 1.4]} \\
17(1.9) \\
457(52.0) \\
404(46.1)\end{array}$ & $\begin{array}{l}<0.01 \\
<0.01\end{array}$ \\
\hline $\begin{array}{l}\text { Accessibility in residential area: Number of services } \\
\text { close }{ }^{1} \text { to residential location } \\
\text { As a continuous variable: [Median; } Q 1-Q 3] \\
\text { Small number }(<100) \\
\text { Intermediate number }(100-200) \\
\text { Large number }(>200)\end{array}$ & $\begin{array}{l}{[122 ; 60-206]} \\
151(44.3) \\
100(29.3) \\
90(26.4)\end{array}$ & $\begin{array}{l}{[100 ; 45-205]} \\
384(50.3) \\
184(24.1) \\
196(25.6)\end{array}$ & $\begin{array}{l}{[126 ; 53-241]} \\
395(45.0) \\
192(21.9) \\
291(33.1)\end{array}$ & $\begin{array}{l}0.12 \\
0.09\end{array}$ \\
\hline $\begin{array}{l}\text { Accessibility in activity space: Mean number of services } \\
\text { close }^{1} \text { to residential and regular activity locations } \\
\text { As a continuous variable: [Median; } Q 1-Q 3 \text { ] } \\
\text { Small number }(<100) \\
\text { Intermediate number }(100-200) \\
\text { Large number }(>200)\end{array}$ & $\begin{array}{l}{[150 ; 84-236]} \\
106(31.1) \\
126(36.9) \\
109(32.0)\end{array}$ & $\begin{array}{l}{[161 ; 95-325]} \\
210(27.5) \\
236(30.9) \\
318(41.6)\end{array}$ & $\begin{array}{l}{[376 ; 177-609]} \\
108(12.3) \\
193(15.8) \\
631(71.9)\end{array}$ & $<0.01$ \\
\hline
\end{tabular}

${ }^{1} 800$-meter circular buffer

No significant gradient was found for the number of services close to the residential location according to education level and the proportion of respondents with spatial accessibility to a large number of services (more than 200) close to their place of residence was broadly similar among the three educational categories (Table 2). By contrast, we observed a significant educational gradient in the number of services in the activity space, with a median of 150 services among respondents with a High school education or less, 161 services among respondents with Post-secondary education, and 376 among respondents with a University education. The proportion of respondents for whom a large number of services (more than 200) was accessible in their activity space was found to increase gradually with educational attainment $(32.0 \%, 41.6 \%$ and $71.9 \%$ from least to most educated). A moderate positive correlation (0.459) was observed between residential and activity space accessibility measures, suggesting that although they are associated, they are not equivalent.

\section{Variation in the risk of reporting poor mental health}

Results for the association between self-rated mental health and socio-demographic and accessibility variables are shown in Table 3. In bivariate models (Models A), the probability of reporting poor mental health was higher for female participants, those in the lowest education category, those without access to a car nor a monthly public transit pass, and those with a small number of services around their activity locations (i.e., a low activity space accessibility). 
Table 3. Associations between poor mental health and socio-demographic variables and residential/activity space accessibility to services among ISIS study respondents (Montreal, Canada, 2011-2012).

\begin{tabular}{|c|c|c|c|c|}
\hline & $\begin{array}{l}n(\% \text { of } \\
1,983)\end{array}$ & $\begin{array}{l}\text { Model A } \\
\text { Bivariate }\end{array}$ & $\begin{array}{l}\text { Model B } \\
\text { Adjusted }\end{array}$ & $\begin{array}{l}\text { Model C } \\
\text { Adjusted }\end{array}$ \\
\hline & mental health & Odd Ratios [95\% CI & & \\
\hline $\begin{array}{l}\text { Sex } \\
\text { Female } \\
\text { Male }\end{array}$ & $\begin{array}{l}120(10.69) \\
63(7.33)\end{array}$ & $\begin{array}{l}1.51[1.10-2.08]^{*} \\
1\end{array}$ & $\begin{array}{l}1.63[1.17-2.25]^{* *} \\
1\end{array}$ & $\begin{array}{l}1.64[1.18-2.27]^{* *} \\
1\end{array}$ \\
\hline $\begin{array}{l}\text { Living with parents } \\
\text { Yes } \\
\text { No }\end{array}$ & $\begin{array}{l}141(9.3) \\
42(9.0)\end{array}$ & $\begin{array}{l}1.04[0.73-1.50] \\
1\end{array}$ & / & l \\
\hline $\begin{array}{l}\text { Number of out-of-home activity locations } \\
\text { None } \\
\text { Small number (1-2) } \\
\text { Large number (3-8) }\end{array}$ & $\begin{array}{l}15(11.81) \\
104(9.16) \\
64(8.88)\end{array}$ & $\begin{array}{l}1.37[0.76-2.50] \\
1.03[0.75-1.43] \\
1\end{array}$ & / & l \\
\hline $\begin{array}{l}\text { Access to motorized transportation } \\
\text { No access to car, no monthly public transit pass } \\
\text { Monthly public transit pass only } \\
\text { Access to car only } \\
\text { Access to car and monthly public transit pass }\end{array}$ & $\begin{array}{l}26(19.8) \\
53(9.4) \\
42(8.6) \\
62(7.7)\end{array}$ & $\begin{array}{l}2.95[1.79-4.87]^{* *} \\
1.23[0.84-1.81] \\
1.13[0.75-1.70] \\
1\end{array}$ & $\begin{array}{l}2.87[1.67-4.92]^{* *} \\
1.22[0.82-1.80] \\
1.14[0.73-1.75] \\
1\end{array}$ & $\begin{array}{l}2.79[1.63-4.78]^{* *} \\
1.21[0.82-1.78] \\
1.07[0.69-1.66] \\
1\end{array}$ \\
\hline
\end{tabular}

$* P$-value $<0.05 ; * * P$-value $<0.01$

1800 -meter circular buffer

The number of services around the residential location was not associated with mental health, nor was living with one's parents. In adjusted models, most of these statistically significant associations persisted, although they were slightly stronger for sex, weaker for motorized transportation, and became non-significant for educational level. In adjusted models, service accessibility in residential areas was not associated with poor mental health (Model B) while service accessibility in activity spaces was (Model C). After adjustment for sex, age, access to motorized transportation and educational attainment, 
the risk of reporting poor mental health remained higher for participants with a small rather than a large accessibility to services in activity spaces $(\mathrm{OR}=1.54 ; 95 \% \mathrm{CI}=1.04$ 2.28; see Model C). We also explored including 'living with parents' and 'number of outof-home activities' in the adjusted models but the two variables showed no significant association with the mental health outcome and were finally omitted in the multivariate analysis (Models B and C).

\section{Socially-differentiated associations between self-rated mental health and spatial accessibility to services}

Table 4 shows the association between poor mental health and residential or activity space accessibility, globally and by educational attainment. Service accessibility in the residential area was not associated with mental health in the full sample nor in stratified analyses, and tests for interactions and heterogeneous effects did not reach statistical significance. Conversely, low accessibility to services in the activity space was significantly associated with poor mental health. The regression-based test for interaction in the full sample $(\mathrm{p}=0.02)$ and the Cochran $\mathrm{Q}$ tests for heterogeneous effects of intermediate accessibility $(p=0.07)$ and particularly for low accessibility $(p=0.01)$ suggested that education level modified the accessibility-mental health associations. Low accessibility increased the likelihood of reporting poor mental health in participants from both the High school and Postsecondary education groups. Among these two groups, there was a gradient whereby the lower the accessibility, the higher the risk of poor mental health. By contrast, accessibility levels were not linked to mental health among respondents with a University education.

Table 4. Odds of reporting poor mental health according to residential or activity space accessibility to services in the three educational subgroups (ISIS study, Montreal, Canada, 2011-2012).

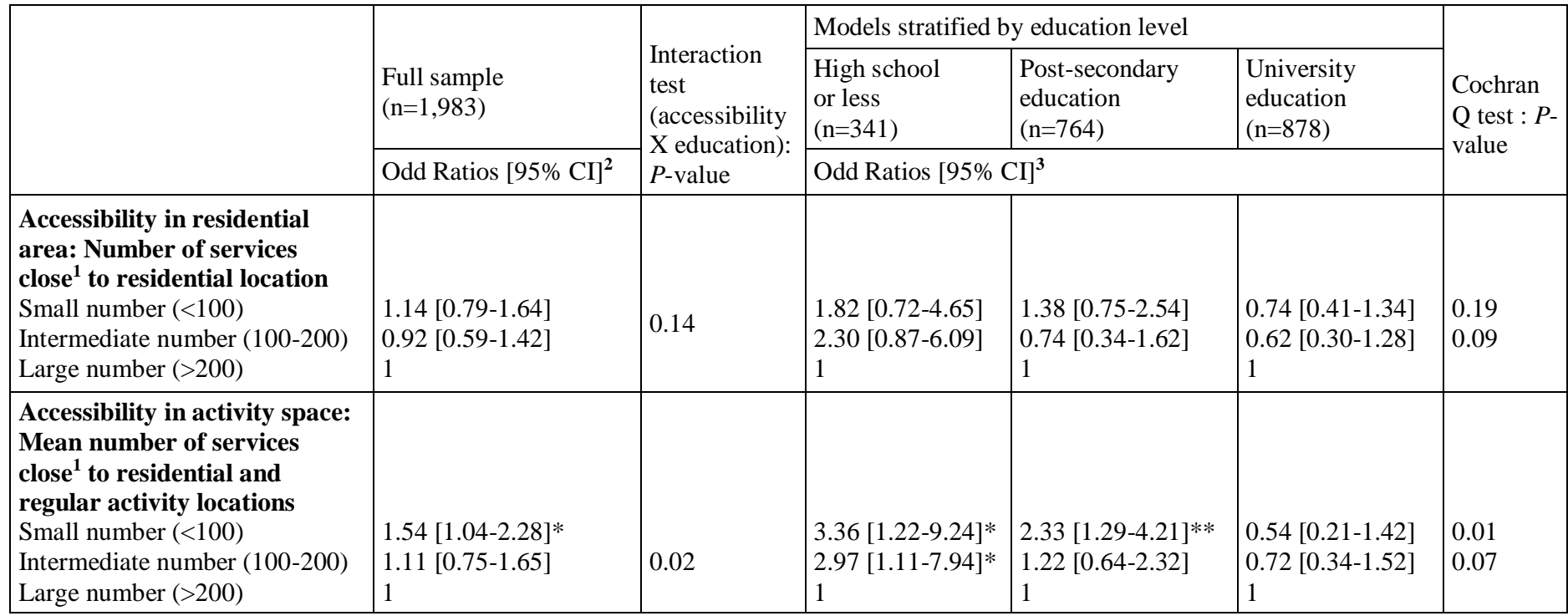

$* P$-value $<0.05 ; * * P$-value $<0.01$

1 800-meter circular buffer

${ }^{2}$ Adjustment on sex, age, access to motorized transportation and education level

3 Adjustment on sex, age and access to motorized transportation 
Sensitivity analyses revealed similar interactions and heterogeneous effects $(\mathrm{p}<0.05)$ when using 500- and 800-metre road-network buffers instead of 500-metre circular buffers (models not shown).

\section{Discussion}

We observed that less educated young adults not only had a lower spatial accessibility to services than their more educated counterparts, they also were more vulnerable to lower numbers of surrounding services than more educated young adults: lower service accessibility was associated with poorer mental health among the less educated, but not the more educated, young adults. Three main findings are being discussed below, specifically (1) the social gradient in spatial accessibility to services; (2) the difference in associations between self-reported mental health and service accessibility depending on residential vs. activity space measures and; (3) the fact that disadvantaged groups were disproportionately more affected by low spatial accessibility compared to socially advantaged groups.

\section{The social gradient in spatial accessibility to services}

As noted by several authors (e.g., Pearce et al. 2007) a deprivation gradient in local (i.e., residential) health resource accessibility is often assumed, although the evidence is equivocal. In this study, an educational gradient was observed in service accessibility in the activity space but not in the residential area (Table 2). If activity space exposure had not been considered, we could have incorrectly concluded - using accessibility in the residential area only - that educational attainment was not linked to service accessibility. Research exploring social inequalities in accessibility should go beyond where one lives, to also include where one works and plays, thereby optimizing the identification of possible socio-environmental inequalities (Shareck et al, 2014b). However, to further push the full 'daycourse' perspective of place effects, one should also consider both individuals' schedules and the opening hours of services (Neutens et al. 2010; Vallée 2017; Widener et al. 2017). Such a space-time approach (which requires temporal data that were unavailable in the ISIS study) would more accurately reflect everyday constraints and opportunities, and lead to uncovering possible social gradients in accessibility or exposure to environmental conditions.

\section{Residential vs. activity locations for measuring place effects on health}

We found differential associations between accessibility to services and mental health by education level when accessibility was measured in the activity space, but not in the residential area alone (Table 3 ). When we considered spatial accessibility to services in the residential area, we found neither a significant association between spatial accessibility and mental health nor did we find a significant interaction between spatial accessibility and level of education (Table 4). In other words, an exclusive focus on the residential area would have led us to conclude that mental health was not related to spatial accessibility to services. This conclusion would have suffered from the 'local' trap (Cummins 2007) since we, in fact, found significant associations and interactions when considering activity space accessibility. Our findings lead us to wonder whether other empirical studies on health which did not find significant interactions between residential features and individual socio-economic position (eg., Stafford et al. 2001) would have 
found different results if they had considered people's activity spaces. Future analyses of vulnerability to place effects on health would gain from not being restricted to residential environments only.

\section{What is behind the socially differentiated vulnerability to service accessibility?}

Lower service accessibility was associated with poorer mental health among less educated young adults but not among the more educated (Table 4). This finding offers a good illustration of the non-uniform relationship between place-based features and health outcomes. At least three arguments might explain why the 'objectively' small number of services close to residential and activity locations may induce a differential burden for social groups. These three arguments are illustrated in a fictive city in Figure 1.

Figure 1. Socio-spatial mechanisms behind the socially-differentiated vulnerability to services accessibility

Three arguments to explain why people of different socio-economic position who share the same regular activity locations may have a different access to services

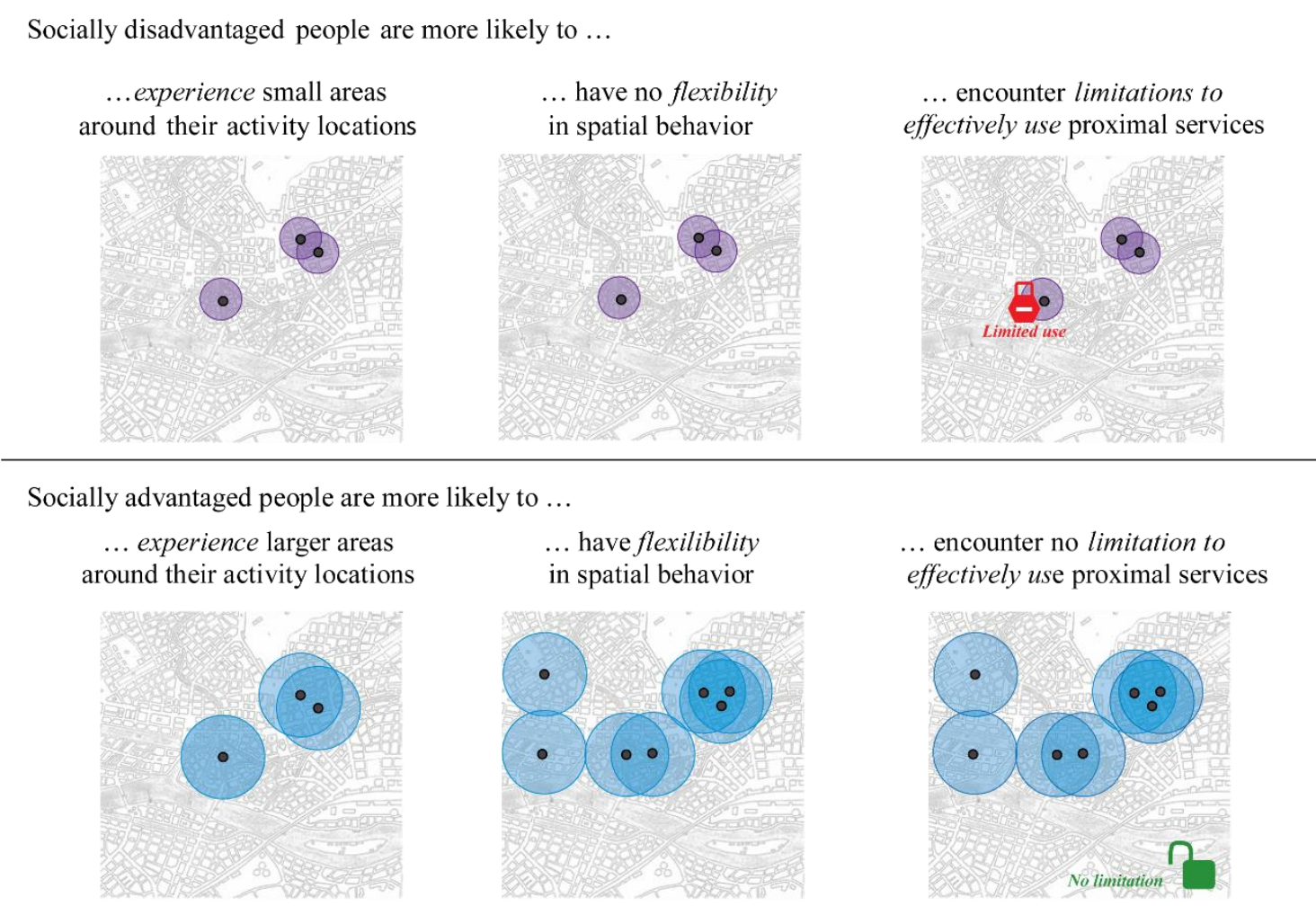

(i) Place experiences around residential and activity locations. Socially advantaged people may engage with larger areas around their regular activity locations than socially disadvantaged ones, and may thus benefit from a larger number of services. Uniform areas (in our case, 800-meter circular buffers) around residential and activity locations may not necessarily capture the services which are actually spatially accessible. Recent studies have in fact underlined that constant-size circular or road-network buffers do not coincide with self-defined neighbourhoods, and that socially advantaged people 
experience larger areas around their residence than their more socially disadvantaged counterparts (Vallée et al. 2015, 2020). By counting services located within uniform areas, we have neglected socially-patterned place experiences, and thus potentially underestimated the number of services socially advantaged people can effectively access, and overestimated those that are spatially accessible for more socially disadvantaged people. Socially-patterned place experiences could constitute one piece of the puzzle to explain socially-differentiated vulnerability to place effects.

(ii) Flexibility in spatial behaviour. Compared to socially disadvantaged people, socially advantaged people generally dispose of a larger mobility potential or 'motility' (Kaufmann 2002) and a larger range of familiar places from which they can choose - if and when they wish - to access the services they need. They benefit from better access to private motorized transportation and from public transit more adapted to their travel needs (e.g., Golledge and Stimson 1997; Farber, Ritter, and Fu 2016. See also Table 2). By contrast, socially disadvantaged people tend to be more tied to specific residential and activity places. They can less easily choose where and when to perform daily activities. This socially differentiated flexibility in spatial behaviour is not captured when using a predefined list of regular activity (discouraging respondents to report more informal or less regular activities) and when measuring the mean number of services around residential and activity locations. By averaging the number of services around residential and activity locations, we have likely underestimated the cumulative number of services each young adult can effectively access. However, this underestimation more strongly affected socially advantaged people since they reported a larger number of out-of-home activity locations (see Table 2). Flexibility in spatial behaviour could then constitute another piece of the puzzle to explain socially-differentiated vulnerability to place effects.

(iii) Rules regulating effective access to services. Compared to socially disadvantaged people, socially advantaged people may encounter fewer financial, organizational, and cultural limitations to effectively using services located close to their residential and activity locations. Over and above sheer proximity, the extent to which a population 'gains access' to resources depends on socially determined rules such as price and civic or informal rights (Bernard et al. 2007). We might then suppose that a low spatial accessibility has a stronger negative impact when it is compounded by other accessibility constraints. The presence of only a few services may not negatively impact those who can convert every available resource into an accessible resource. In addition to the rules limiting their effective access to proximal services, socially disadvantaged people might encounter larger difficulties travelling to better serviced neighbourhoods due to unwritten rules or norms signifying they are unwelcome, or because they feel "out of place" (Shareck et al., 2014b). Socially-differentiated vulnerability to potential access to services also needs to be understood in light of the rules regulating effective access to services.

Because of differences in place experiences and in the flexibility of spatial behaviour, and due to rules regulating effective access to services, not all social groups have the same abilities to cope with an 'objective' lack of services close to their residential and activity locations. These three arguments, which would merit further theoretical and empirical investigation, may help to better understand the socio-spatial mechanisms making some people 'truly disadvantaged'. 


\section{Limitations}

In the introduction we argued that service accessibility may operate on mental health via social inclusion and spatial justice. Since our study did not include any indicators of respondents' sense of social inclusion, it was impossible to explore the ways in which service accessibility might influence people's feeling of inclusion (or exclusion) in the city and in society. Further empirical analysis (whether using qualitative or quantitative data) would be necessary to fully explore the causal pathways between service accessibility, social inclusion and mental health. We recommend that future studies assess whether similar findings are observed for other age groups and for other mental health outcomes (e.g., validated indicators of self-reported mental health measured using the Short Form 12 (SF-12) health survey). Examining individuals with internalizing disorders or with cognitive challenges could also help us better understand how people experience places and access services in their everyday life.

Furthermore, cross sectional analyses such as those presented here need to be carefully discussed in terms of causality. Specifically, it is not known (i) if limited service accessibility leads to poor mental health for socially disadvantaged young adults, or (ii) if poor mental health leads young adults (and only the socially disadvantaged ones) to restrict their activity space and thus their accessibility to services. It would be insightful to analyse longitudinal data in order to consider the possibility 'reverse causation', a problem which affects all cross-sectional studies.

Finally this empirical study took place in Montreal, Canada, an urban area. It would be useful to extend it to other cities and rural settings (ie. cities and areas with different densities of services, different spatial distributions of activity locations or different mobility habits and norms) to confirm that socially disadvantaged people are not only those with lower spatial accessibility to services in everyday life, but also those most vulnerable to lower numbers of services around their activity locations when considering their mental health.

\section{Further policy implications}

Beyond self-rated mental health itself, our findings about social trends in exposure and vulnerability to service accessibility underscore the double burden facing socially disadvantaged groups. In light of this evidence-based inequity, we encourage policy makers and urban planners to not only increase service density in deprived areas but also to implement interventions specifically aimed at socially disadvantaged people so that they can (i) experience larger areas around their residential and activity locations, (ii) be more flexible in their spatial behaviour, and (iii) convert every available resource into a truly accessible resource. Based on these objectives, 'monitoring indicators' could be defined to identify programs (eg., '15-minute city' plans) that have been successful at reducing - or at least preventing - the widening of social inequalities in service accessibility in people's everyday lives.

\section{Conclusion}

While common in the climate change literature (Cutter and Finch 2008; Reid 2013), the notion of 'social vulnerability' is less frequently encountered in the literature on place effects, even though it is highly relevant. Behind the term 'social vulnerability' are two 
non-mutually exclusive mechanisms (Diderichsen, Hallqvist, and Whitehead 2019): one that entails that socially disadvantaged populations are more exposed to deleterious places ('differential exposure'), and another which suggests they lack the resources or capabilities to cope with, and adapt to, these nuisances ('differential effect'). In the place effects literature, it is relatively frequent to explore the first mechanism and to conclude that socially disadvantaged populations are more vulnerable because they are more 'exposed' to deleterious places (Galster 2012) and then 'at higher risk of risks' (Frohlich and Potvin 2008). However, it is less frequent to analyse the ways in which socially disadvantaged populations might be disproportionately affected by place-based features, and even rarer to extend these analyses to daily activity spaces. In addition to providing empirical evidence regarding this latter gap in the literature, we have put forward in this paper several lines of enquiry to investigate the 'concentration effects' and gain insights into the way(s) socially disadvantaged people may be particularly vulnerable to service accessibility in everyday life.

\section{Funding details}

The ISIS cohort was supported by a CIHR Operating Grant (MOP-110977). The work was also been supported by Université Paris Sorbonne Cités - USPC (AAP2RELAT15RDX) and CNRS (PICS 2017-2019 - RELATHEALTH). KLF co-holds the Myriagone Chaire McConnell-UdM on Knowledge Mobilisation with Youth.

Conflict of interest: None declared.

\section{Acknowledgements}

We thank Geetanjali Datta for her comments on a preliminary version of this paper. We would like to acknowledge Tarik Benmarhnia for his support with estimating heterogeneous effects and with Cochran Q tests. We also thank ISIS respondents.

\section{References}

Ahmad, F., A. K. Jhajj, D. E. Stewart, M. Burghardt, and A. S. Bierman. 2014. Single item measures of self-rated mental health: a scoping review. BMC Health Services Research 14 (1).

Benmarhnia, T., S. Deguen, J. S. Kaufman, and A. Smargiassi. 2015. Review Article: Vulnerability to Heat-related Mortality. Epidemiology 26 (6):781-793.

Bernard, P., R. Charafeddine, K. L. Frohlich, M. Daniel, Y. Kestens, and L. Potvin. 2007. Health inequalities and place: A theoretical conception of neighbourhood. Social Science \& Medicine 65 (9):1839-1852.

Betancur, J. 2011. Gentrification and Community Fabric in Chicago. Urban Studies 48 (2):383-406. 
Bowman, D. 2010. Sen and Bourdieu: understanding inequality. Melbourne: University of Melbourne \& the Brotherhood of St Laurence.

Chaix, B., and P. Chauvin. 2003. Tobacco and alcohol consumption, sedentary lifestyle and overweightness in France: a multilevel analysis of individual and area-level determinants. European Journal of Epidemiology 18:531-538.

Cicognani, E., C. Albanesi, and B. Zani. 2008. The impact of residential context on adolescents' subjective well-being. Journal of Community \& Applied Social Psychology 18 (6):558-575.

Cummins, S. 2007. Commentary: investigating neighbourhood effects on health-avoiding the "local trap." International Journal of Epidemiology 36 (2):355-7.

Cummins, S., S. Curtis, A. V. Diez-Roux, and S. Macintyre. 2007. Understanding and representing "place" in health research: A relational approach. Social Science \& Medicine 65:1825-1838.

Cummins, S., M. Stafford, S. Macintyre, M. Marmot, and A. Ellaway. 2005. Neighbourhood environment and its association with self-rated health: evidence from Scotland and England. Journal of Epidemiology and Community Health 59:207-213.

Cutter, S. L., and C. Finch. 2008. Temporal and spatial changes in social vulnerability to natural hazards. Proceedings of the National Academy of Sciences 105 (7):2301-2306.

Delbosc, A. 2012. The role of well-being in transport policy. Transport Policy 23:25-33.

Depeau, S. 2017. Children in cities: the delicate issue of well-being and quality of urban life. In Handbook of Environmental Psychology and Quality of Life Research, eds. G. Fleury-Bahi, E. Pol, and O. Navarro, 345-368. Springer. Cham, Switzerland

Diderichsen, F., J. Hallqvist, and M. Whitehead. 2019. Differential vulnerability and susceptibility: how to make use of recent development in our understanding of mediation and interaction to tackle health inequalities. International Journal of Epidemiology 48 (1):268-274.

Dubreuil, A., J. Vallée, M. Shareck, and K. Frohlich. 2020. [Changes in activity spaces during the transition to adulthood (Montreal, Canada)] L'évolution des espaces d'activité lors de la transition vers l'âge adulte (Montréal, Canada). Revue Jeunes et Société 5 (1):71-98.

Eriksson, I., A.-L. Undén, and S. Elofsson. 2001. Self-rated health. Comparisons between three different measures. Results from a population study. International Journal of Epidemiology 30 (2):326-333.

Farber, S., B. Ritter, and L. Fu. 2016. Space-time mismatch between transit service and observed travel patterns in the Wasatch Front, Utah: A social equity perspective. Travel Behaviour and Society 4:40-48.

Farrington, J., and C. Farrington. 2005. Rural accessibility, social inclusion and social justice: towards conceptualisation. Journal of Transport Geography 13 (1):1-12.

Fol, S., and C. Gallez. 2014. Social inequalities in urban access. Better ways of assessing transport improvements. In Urban Access for the 21 st Century. Finance and governance models for transport infrastructure, ed. E. D. Sclar, M. Lönnroth, and C. Wolmar, 46-86. London:Routledge. 
Frohlich, K., and L. Potvin. 2008. Transcending the Known in Public Health Practice: The Inequality Paradox: The Population Approach and Vulnerable Populations. American Journal of Public Health 98 (2):216-221.

Frohlich, K., M. Shareck, J. Vallée, T. Abel, R. Agouri, M. Cantinotti, M. Daniel, C. Dassa, G. Datta, T. Gagné, B.-S. Leclerc, Y. Kestens, J. O’Loughlin, and L. Potvin. 2017. Cohort Profile: The Interdisciplinary Study of Inequalities in Smoking (ISIS). International Journal of Epidemiology 46 (2):e4-e4.

Gagné, T., A. E. Ghenadenik, M. Shareck, and K. L. Frohlich. 2018. Expected or Completed? Comparing Two Measures of Education and Their Relationship with Social Inequalities in Health Among Young Adults. Social Indicators Research 135 (2):549_ 562.

Galobardes, B., M. Shaw, D. Lawlor, J. Lynch, and G. Davey Smith. 2006. Indicators of socioeconomic position (part 1). Journal of Epidemiology and Community Health 60 (1):7-12.

Galster, G. 2012. The mechanism(s) of neighbourhood effects : theory, evidence, and policy implications. In Neighbourhood Effects Research: New Perspectives, eds. M. van Ham, D. Manley, N. Bailey, L. Simpson, and D. Maclennan, 23-56. Dordrecht: Springer Netherlands.

Golledge, R., and R. Stimson. 1997. Spatial Behaviour - A geographic perspective. New York: Guilford Press.

Grenier, S., M. Préville, R. Boyer, and K. O’Connor. 2009. Prevalence and correlates of obsessive-compulsive disorder among older adults living in the community. Journal of Anxiety Disorders 23 (7):858-865.

Hägerstrand, T. 1970. What about people in regional science? Papers of Regional Science Association 24:7-21.

Idler, E. L., and Y. Benyamini. 1997. Self-rated health and mortality: a review of twentyseven community studies. Journal of Health and Social Behavior 38 (1):21-37.

Inagami, S., D. A. Cohen, and B. K. Finch. 2007. Non-residential neighborhood exposures suppress neighborhood effects on self-rated health. Social Science \& Medicine 65:1779-1791.

Jones, M. 2009. Phase space: geography, relational thinking, and beyond. Progress in Human Geography 33 (4):487-506.

Jylhä, M. 2009. What is self-rated health and why does it predict mortality? Towards a unified conceptual model. Social Science \& Medicine 69 (3):307-316.

Kaufmann, V. 2002. Re-thinking mobility. Contemporary sociology. Aldershot: Ashgate.

Kim, D. 2008. Blues from the neighborhood? Neighborhood characteristics and depression. Epidemiologic Reviews 30 (1):101-117.

van Lenthe, F., and J. Mackenbach. 2002. Neighbourhood deprivation and overweight: the GLOBE study. International Journal of Obesity 26:234-40.

Leslie, E., and E. Cerin. 2008. Are perceptions of the local environment related to neighbourhood satisfaction and mental health in adults? Preventive Medicine 47 (3):273278. 
Liu, H., F. Li, J. Li, and Y. Zhang. 2017. The relationships between urban parks, residents' physical activity, and mental health benefits: A case study from Beijing, China. Journal of Environmental Management 190:223-230.

Maas, J., R. Verheij, P. Groenewegen, S. de Vries, and P. Spreeuwenberg. 2006. Green space, urbanity, and health: how strong is the relation? Journal of Epidemiology and Community Health 60 (7):587-592.

Macintyre, S., A. Ellaway, and S. Cummins. 2002. Place effects on health: how can we conceptualise, operationalise and measure them? Social Science \& Medicine 55 (1):12539.

Mackenbach, J. P. 2012. The persistence of health inequalities in modern welfare states: The explanation of a paradox. Social Science \& Medicine 75 (4):761-769.

Mair, C., A. V. Diez Roux, and S. Galea. 2008. Are neighbourhood characteristics associated with depressive symptoms? A review of evidence. Journal of Epidemiology and Community Health 62 (11):940-946.

Mawani, F. N., and H. Gilmour. 2010. Validation of self-rated mental health. Health Reports 21 (3):61-75.

Neutens, T., T. Schwanen, F. Witlox, and P. de Maeyer. 2010. Evaluating the Temporal Organization of Public Service Provision Using Space-Time Accessibility Analysis. Urban Geography 31 (8).

Oakes, J. M., K. E. Andrade, I. M. Biyoow, and L. T. Cowan. 2015. Twenty Years of Neighborhood Effect Research: An Assessment. Current Epidemiology Reports 2 (1):8087.

Passchier-Vermeer, W., and W. F. Passchier. 2000. Noise exposure and public health. Environmental Health Perspectives 108 (suppl 1):123-131.

Patel, V., A. J. Flisher, S. Hetrick, and P. McGorry. 2007. Mental health of young people: a global public-health challenge. The Lancet 369 (9569):1302-1313.

Pearce, J., K. Witten, R. Hiscock, and T. Blakely. 2007. Are socially disadvantaged neighbourhoods deprived of health-related community resources? International Journal of Epidemiology 36 (2):348-55.

Potvin, S., P. Apparicio, and A.-M. Séguin. 2019. The spatial distribution of noise barriers in Montreal: A barrier to achieve environmental equity. Transportation Research Part D: Transport and Environment 72:83-97.

Reid, M. 2013. Disasters and Social Inequalities. Sociology Compass 7 (11):984-997.

Sallis, J. F., L. D. Frank, B. E. Saelens, and M. K. Kraft. 2004. Active transportation and physical activity: opportunities for collaboration on transportation and public health research. Transportation Research Part A: Policy and Practice 38 (4):249-268.

Schulenberg, J. E., A. J. Sameroff, and D. Cicchetti. 2004. The transition to adulthood as a critical juncture in the course of psychopathology and mental health. Development and Psychopathology 16 (04). 799-806

Seabrook, J. A., and W. R. Avison. 2012. Socioeconomic Status and Cumulative Disadvantage Processes across the Life Course: Implications for Health Outcomes: 
Socioeconomic Status and Cumulative Disadvantage. Canadian Review of Sociology/Revue canadienne de sociologie 49 (1):50-68.

Shareck, M., Y. Kestens, and L. Gauvin. 2013. Examining the spatial congruence between data obtained with a novel activity location questionnaire, continuous GPS tracking, and prompted recall surveys. International Journal of Health Geographics 12 (1):40.

Shareck, M., K. Frohlich, and Y. Kestens. 2014a. Considering daily mobility for a more comprehensive understanding of contextual effects on social inequalities in health: a conceptual proposal. Health \& Place 29:154-60.

Shareck, M., Y. Kestens, and K. L. Frohlich. 2014b. Moving beyond the residential neighborhood to explore social inequalities in exposure to area-level disadvantage: Results from the Interdisciplinary Study on Inequalities in Smoking. Social Science \& Medicine 108:106-14.

Shareck, M., G. D. Datta, J. Vallée, Y. Kestens, and K. L. Frohlich. 2020. Is smoking cessation in young adults sssociated with tobacco retailer availability in their activity space? Nicotine \& Tobacco Research 22 (4):512-521.

Sheller, M., and J. Urry. 2006. The New Mobilities Paradigm. Environment and Planning A: Economy and Space 38 (2):207-226.

Shortt, N. K., E. Rind, J. Pearce, R. Mitchell, and S. Curtis. 2018. Alcohol Risk Environments, Vulnerability, and Social Inequalities in Alcohol Consumption. Annals of the American Association of Geographers 108(5):1210-1227.

Stafford, M., M. Bartley, R. Mitchell, and M. Marmot. 2001. Characteristics of individuals and characteristics of areas: investigating their influence on health in the Whitehall II study. Health \& Place 7:117-129.

Stafford, M., and M. Marmot. 2003. Neighbourhood deprivation and health: does it affect us all equally? International Journal of Epidemiology 32 (3):357-366.

Vallée, J. 2009. [Spatial health disparities within city: the case of Vientiane, Lao PDR] Les disparités spatiales de santé en ville. L'exemple de Vientiane (Laos). Cybergeo 477.

. 2017. The daycourse of place. Social Science \& Medicine 194:177-181.

Vallée, J., E. Cadot, F. Grillo, I. Parizot, and P. Chauvin. 2010. The combined effects of activity space and neighbourhood of residence on participation in preventive health-care activities: The case of cervical screening in the Paris metropolitan area (France). Health \& Place 16:838-852.

Vallée, J., E. Cadot, C. Roustit, I. Parizot, and P. Chauvin. 2011. The role of daily mobility in mental health inequalities: The interactive influence of activity space and neighbourhood of residence on depression. Social Science \& Medicine 73 (8):1133-1144.

Vallée, J., and P. Chauvin. 2012. Investigating the effects of medical density on healthseeking behaviours using a multiscale approach to residential and activity spaces: results from a prospective cohort study in the Paris metropolitan area, France. International Journal of Health Geographics 11:54.

Vallée, J., G. Le Roux, B. Chaix, Y. Kestens, and P. Chauvin. 2015. The 'constant size neighbourhood trap' in accessibility and health studies. Urban Studies 52 (2):338-357. 
Vallée, J., M. Shareck, G. Le Roux, Y. Kestens, and K. L. Frohlich. 2020. Is accessibility in the eye of the beholder? Social inequalities in spatial accessibility to health-related resources in Montréal, Canada. Social Science \& Medicine 245:112702.

Veenstra, G. 2011. Mismatched racial identities, colourism, and health in Toronto and Vancouver. Social Science \& Medicine (1982) 73 (8):1152-1162.

Weich, S., L. Twigg, G. Holt, G. Lewis, and K. Jones. 2003. Contextual risk factors for the common mental disorders in Britain: a multilevel investigation of the effects of place. Journal of Epidemiology and Community Health 57 (8):616-21.

Widener, M. J., L. Minaker, S. Farber, J. Allen, B. Vitali, P. C. Coleman, and B. Cook. 2017. How do changes in the daily food and transportation environments affect grocery store accessibility? Applied Geography 83:46-62.

Wilson, W. J. 1987. The truly disadvantaged: the inner city, the underclass, and public policy. Chicago: Univ. of Chicago Press.

\section{Author information}

JULIE VALLÉE holds a full-time research position in geography in the French National Center for Scientific Research (CNRS), Géographie-cités Laboratory, ParisAubervilliers, 93300, France. E-mail: julie.vallee@parisgeo.cnrs.fr. Her research investigates spatial mechanisms of social (health) inequalities, with a focus on neighborhood effects, people's daily mobility, and changes in urban segregation throughout the day. She is the leader of the Mobiliscope interactive platform (www.mobiliscope.cnrs.fr), which reveals hourly population dynamics in a wide range of cities and their peripheral areas.

MARTINE SHARECK is Assistant Professor in the Department of Community Health Sciences at the Universite de Sherbrooke, Sherbrooke QC J1H 5N4, Canada. She holds a Tier 2 Canada Research Chair on Urban Health Equity Among Young People. E-mail: martine.shareck@usherbrooke.ca. Her research interests include uncovering the mechanisms linking urban environmental features, social determinants of health, and health outcomes among young people, and the evaluation of innovative interventions in the urban environment to understand what works to reduce social inequalities in health, how, and for whom.

YAN KESTENS is a Professor in the Department of Social and Preventive Medicine at the School of Public Health, University of Montreal, Montreal QC H3N 1X7, Canada. Email: yan.kestens@umontreal.ca. His research explores how urban transformations can improve population health and equity.

KATHERINE L. FROHLICH is Full Professor and Co-Chair holder of the Myriagone UdM-McConnell Chair on Youth Knowledge Mobilization at the School of Public Health, University of Montreal, Montreal QC H3N 1X7, Canada. E-mail: Katherine.frohlich@umontreal.ca. Her research interests include social inequalities in urban youth health. 